\title{
Analise de Velocidade Não Hiperbólica em Dados Sísmicos da Bacia do Jequitinhonha
}

Francisco G. Ortega, IGEO/UFBA; Amin Bassrei, CPGG/IGEO/UFBA \& INCT-GP; Ellen N. S. Gomes, UFPA \& INCT-GP

Copyright 2014, SBGf - Sociedade Brasileira de Geofísica

Este texto foi preparado para a apresentação no VI Simpósio Brasileiro de Geofísica, Porto Alegre, 14 a 16 de outubro de 2014. Seu conteúdo foi revisado pelo Comite Técnico do VI SimBGf, mas não necessariamente representa a opinião da SBGf ou de seus associados. É proibida a reprodução total ou parcial deste material para propósitos comerciais sem prévia autorização da SBGf.

\section{Abstract}

This paper reviews previous studies and methodologies for the analysis of seismic velocity when the maximum offset is less than maximum depth. The mathematical representation of traveltime for maximum offset is described by a shifted hyperbola. This methodology requires three parameters: traveltimes between source and receivers, normal moveout velocity and coefficient $\mu$. This study suggests that shifted hyperbole can increase resolution more than conventional Dix equation (Dix, 1955). We also show the difference between the conventional equation and shifted hyperbola for AlChalabi (1973) and Castle (1994) methods.

\section{Introdução}

Vários estudos têm demonstrado que a presença de anisotropia sísmica chamada isotropia transversal vertical ou VTI, produz distorções significativas na análise convencional de dados sísmicos, como por exemplo, o fato que a velocidade de sobretempo normal ou NMO não é igual à velocidade RMS na condição de grandes e também de pequenos afastamentos. Este tipo de meio produz um sobretempo normal não hiperbólico, que se manifesta de forma significativa em grandes afastamentos para o caso das ondas PP, ou seja, a onda $P$ que reflete como onda $P$. Já para o caso de uma onda $P$, que na reflexão se converte numa onda $S$, portanto denotada como PS, esse comportamento na curva do tempo de trânsito é observado em todos os afastamentos, sejam grandes ou pequenos (Alkhalifah, 1997). Este conceito de anisotropia é dificilmente visto em levantamentos sísmicos cuja relação afastamento $x$, profundidade $z$ é $x / z<1.5$. Uma solução para este problema é remover os traços sobrecorrigidos e empilhar os demais, obtendo-se assim uma imagem, que, contudo não irá fornecer uma informação mais completa (Calderón, 2003). Num meio cuja relação afastamento profundidade é $x / z<1.5$, a representação matemática do tempo de trânsito entre a fonte e o refletor adicionado ao tempo de trânsito do refletor até o receptor é expressa por uma hipérbole deslocada. Tal hipérbole poderá ser corrigida com o conhecimento de três parâmetros: o tempo de trânsito de ida e volta na condição de afastamento nulo, a velocidade NMO (parâmetro desconhecido) e o momento ponderado do tempo, que será designado por $\mu$. O presente trabalho é formado pelas seguintes partes. Apresentamos uma revisão de duas metodologias que tem por objetivo fazer a correção da curva de tempo de trânsito num meio, definido por AlChalabi (1973) e por Castle (1994) através de uma análise de coerência. Estas duas metodologias foram empregadas em um dado real terrestre 2-D, adquirido na Bacia de Jequitinhonha, Brasil, onde o afastamento máximo entre fonte e receptor era de $3200 \mathrm{~m}$. Nas conclusões, afirmamos que os testes com os dados reais, validaram as duas metodologias, mostrando que nestes casos a utilização do processamento sísmico convencional, para meios isotrópicos, leva a resultados inconsistentes.

\section{Análise de Velocidade Hiperbólica}

O método convencional para análise de velocidade no processamento de dados sísmicos supõe um refletor ideal, isto é, um refletor homogêneo com uma interface plana e com a espessura constante. O meio é ideal, sem perda de energia e também é considerado não dispersivo.

A representação matemática do tempo de trânsito da fonte até o receptor num modelo de camada única é dada por (Dix, 1995):

$$
t_{x}^{2}=t_{0}^{2}+\frac{x^{2}}{V_{n m o}^{2}},
$$

onde $t_{x}$ é o tempo de trânsito ao longo do caminho fonte refletor receptor; $x$ é a distância entre fonte-receptor; $t_{0}$ é o templo duplo de trânsito na posição $x=0$ e $V_{n m o}=z / t_{0} \quad(z$ é a profundidade $)$ é chamada a velocidade normal moveout. Matematicamente a equação (1) representa uma trajetória hiperbólica. A velocidade $V_{\text {nmo }}$ (que é um parâmetro desconhecido do modelo) é deduzida através da análise da trajetória do refletor por um processo de inversão de dados. Para um modelo de múltiplas camadas planas, num meio isotrópico, a velocidade RMS é calculada como:

$$
V_{r m s}=\sqrt{\frac{\sum \Delta \tau_{k} V_{k}^{2}}{\sum \Delta \tau_{k}}},
$$

onde $V_{k}$ é a velocidade intervalar da k-ésima camada, $\Delta \tau_{k}$ é o tempo de trânsito vertical da $k$-ésima camada. $\mathrm{A}$ velocidade $V_{r m s}$ obtida pela expressão acima refere-se ao pacote de $k$ camadas, desde o topo da primeira camada até a base da $k$-ésima camada. Admitindo um 
modelo de um refletor plano horizontal em subsuperfície e organizando os traços sísmicos em famílias de ponto médio comum (CMPs), é possível corrigir o atraso no tempo de chegada das reflexões, ocasionado pelo afastamento entre fonte-receptor, com relação ao tempo duplo de incidência normal. Essa correção, conhecida como normal moveout $(\Delta t)$ é calculada pela equação:

$$
\Delta t=\sqrt{t_{0}^{2}+\left(\frac{x}{v}\right)^{2}}-t_{0} .
$$

Depois que a correção NMO é aplicada nas famílias CMPs, os eventos hiperbólicos associados aos refletores em subsuperfície estarão horizontalizados. Quando os traços de uma família CMP já estão corrigidos do normal moveout, eles são somados, e teremos um traço, conhecido como traço de afastamento nulo.

\section{Método de Al-Chalabi (1973)}

A equação do tempo de trânsito da fonte até o receptor dada por:

$$
T_{s}^{2}=C_{1}+C_{2}^{2} x+C_{3}^{4} x+\ldots+C_{i}^{2 \mathrm{i}-2}+\ldots
$$

onde $x$ é o afastamento e $C_{i}(i=1,2, \ldots, \infty)$ são coeficientes em funções da espessura e da velocidade das camadas. Usando uma variável auxiliar:

$$
a_{i}=2 \sum V_{k}^{2 \mathrm{i}-3} h_{k}, \quad(i=1,2,3, \ldots)
$$

onde $V_{k}$ é a velocidade e $h_{k}$ a espessura intervalar da $k$-ésima camada, são definidos o primeiro e segundo coeficiente como:

$$
\begin{aligned}
& C_{1}=a_{1}^{2}=\left(2 \sum V_{k}^{2 \mathrm{i}-3} h_{k}\right)^{2}=T_{0}^{2,}, \\
& C_{2}=\frac{a_{1}}{a_{2}}=\frac{T_{0}}{2 \sum V_{k}^{2 \mathrm{i}-3} h_{k}}=\frac{1}{V_{r m s}^{2}},
\end{aligned}
$$

onde $T_{0}$ é o tempo de trânsito da fonte até o receptor no afastamento nulo e $V_{r m s}$ a velocidade RMS. O método convencional na análise de velocidade utiliza dois termos da equação (4), de modo que:

$$
T_{c}^{2}=C_{1}+C_{2} x^{2}
$$

A equação (8) amostra o tempo de viagem em um meio isotrópico homogêneo, o truncamento na séria infinita da equação (4) até o segundo termo vem do fato que a velocidade NMO não é igual à velocidade RMS para mais termos (Al-Chalabi, 1973). Al-Chalabi (1973) propõem um terceiro termo na equação (8) que permite incluir as características de um meio que posse a velocidade NMO diferente à velocidade RMS com a seguinte condição:

$$
C_{3} x^{4}>2\left(T_{c}^{2}-T_{s}^{2}\right),
$$

neste caso o terceiro termo poderia sobrecorrigir a série na equação (4) e o resultado pode piorar o truncamento de dois termos na aproximação do tempo de viagem para um refletor real. Na prática $C_{3} x^{4}$ é muito perto de $2\left(T_{c}^{2}-T_{s}^{2}\right)$ o que faz o terceiro gerar resultados muito bons. Al-Chalabi (1973) mostraram que a inclusão de um quarto termo pode não ser necessária para a convergência da série. Pela mesma razão, incluir um quinto termo não seria necessário também para melhorar a convergência.

\section{Método de Castle (1994)}

A representação matemática do tempo de trânsito da energia desde a fonte até o receptor está associada a uma hipérbole deslocada, que irá demandar uma correção de sobretempo normal. Castle (1994), propôs uma aproximação que requer três parâmetros: (i) o tempo de trânsito fonte refletor receptor para afastamento nulo, (ii) a velocidade de sobretempo $\left(V_{n m o}\right)$, e (iii) o chamado momento ponderado $\left(\mu_{j}\right)$.

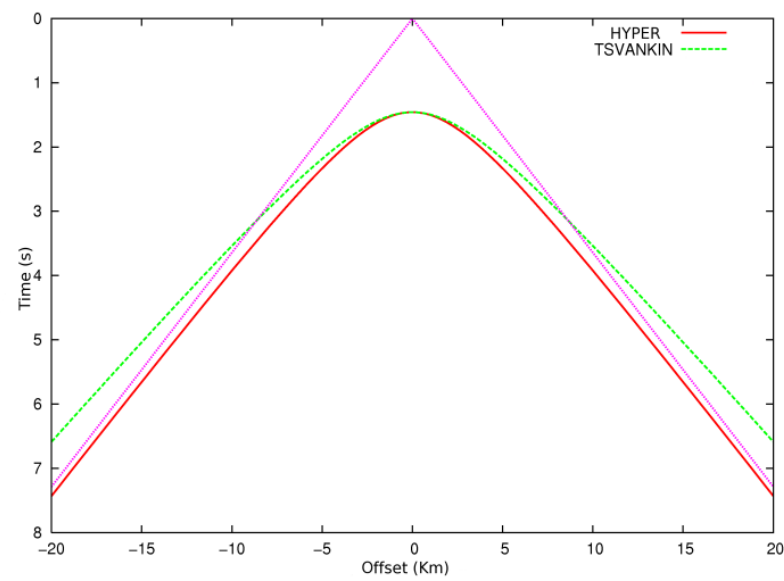

Figura 1 - Tempo de viagem da fonte ao receptor para um modelo com um refletor horizontal a uma profundidade de $2 \mathrm{~km}$, em um meio real (argila). A curva vermelha representa o tempo da equação de Dix (1955) ou hiperbólica e as retas tracejadas suas assíntotas. A curva de cor verde representa a curva do tempo de Alkhalifah e Tsvankin (1995).

A equação (1) descreve uma hipérbole simétrica em relação ao eixo do tempo, cujas assíntotas se intersectam na origem do sistema de coordenadas $(x=0, t=0)$, a Figura 1 ilustra esta geometria com um modelo de um refletor horizontal a uma profundidade de $2 \mathrm{~km}$, em um meio real (argila), onde a curva verde representa o tempo de viagem que se aproxima mais a um refletor real e é dada pela equação descrita por Alkhalifah e Tsvankin (1995). Uma expressão matemática mais exata para a equação de sobretempo normal foi fornecida por Malovichko (1978), e utilizada por Castle (1994), conforme 
a equação:

$$
t=\tau_{s}+\sqrt{\tau_{0}^{2}+\frac{x^{2}}{v^{2}}},
$$

onde $\tau_{0}$ é expresso com

$$
\tau_{0}=\frac{t_{0}}{S}
$$

e $\tau_{s}$ é o tempo de interseção das assíntotas da hipérbole da equação de Dix com o eixo do tempo:

$$
\tau_{s}=\tau_{0}(S-1)
$$

Ainda nas equações acima $t_{0}$ é o tempo duplo vertical (afastamento nulo) e $v$ é uma variável auxiliar, de modo que

$$
v^{2}=S V_{r m s}^{2},
$$

e o fator $S$ é expresso como

$$
S=\frac{\mu_{4}}{\mu_{2}^{2}} .
$$

O valor de $\mu_{j}$, já apresentado como o momento ponderado do tempo, é expresso por

$$
\mu_{j}=\frac{\sum \Delta \tau_{k} V_{k}^{j}}{\sum \Delta \tau_{k}},
$$

sendo $V_{k}$ a velocidade intervalar da $k$-ésima camada e $\Delta \tau_{k}$ o tempo vertical da $k$-ésima camada.

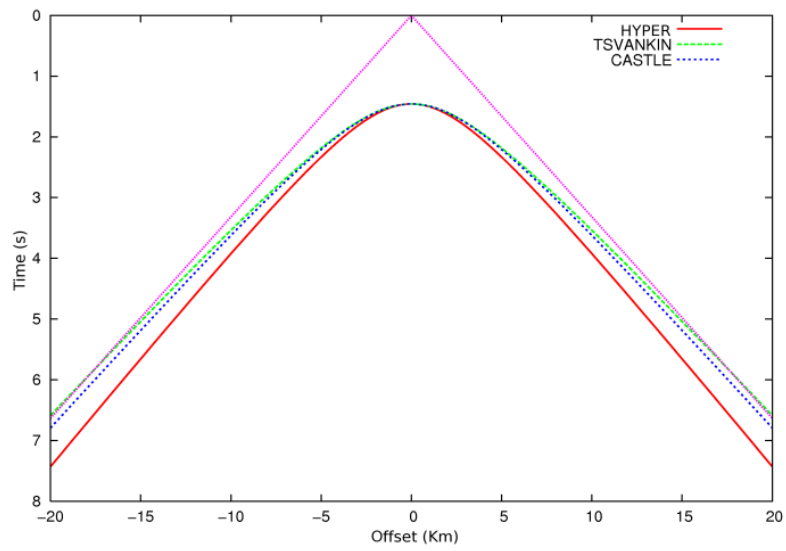

Figura 2 - Tempo de viagem da fonte ao receptor para um modelo com um refletor horizontal a uma profundidade de $2 \mathrm{~km}$, em um meio real (argila). A curva vermelha representa o tempo da equação de Dix (1955) ou hiperbólica. A curva de cor azul representa a equação do tempo de Castle (1994). A curva de cor verde representa a curva do tempo de Alkhalifah e Tsvankin (1995) proveniente do refletor e as retas tracejadas são as assíntotas da equação de Castle.

A Figura 2 ilustra a geometria da equação (10) com o mesmo modelo com um refletor horizontal a uma profundidade de $2 \mathrm{~km}$, em um meio real (argila), e descreve uma hipérbole deslocada simétrica em relação ao eixo do tempo suas assíntotas se intersectam no ponto $\left(x=0, t=\tau_{s}\right)$. A Figura 2 também mostra a curva de tempo da equação de Alkhalifah e Tsvankin (1995).A curva vermelha representa o tempo de viagem fonte refletor receptor da equação de Dix (1955) ou curva hiperbólica. A curva de cor azul representa a equação do tempo de Castle (1994) e a curva de cor verde representa a curva do tempo para a equação de Alkhalifah e Tsvankin (1995) proveniente do refletor. Observa-se que na Figura 2 é evidente, que a equação do sobretempo normal com uma hipérbole deslocada de Castle é uma melhor aproximação à equação de Alkhalifah e Tsvankin (1995) do que a equação convencional de Dix (1955).

\section{Localização e Geologia da Bacia do Jequitinhonha}

A Bacia do Jequitinhonha está localizada na porção nordeste da margem leste brasileira, no litoral sul do Estado da Bahia, em frente à foz do rio Jequitinhonha (ver Figura 3). Ao norte é limitada com a Bacia de CamamuAlmada através do Alto de Olivença, e a sul, com a Bacia de Cumuruxatiba, através do banco vulcânico de Royal Charlotte e sua projeção para o continente. Ocupa uma área de cerca de $10.100 \mathrm{~km}^{2}$, dos quais $9.500 \mathrm{~km}^{2}$ são submersos $\left(7.000 \mathrm{~km}^{2}\right.$ até $1.000 \mathrm{~m}$ de lâmina da água e $2.500 \mathrm{~km}^{2}$ entre $1.000 \mathrm{~m}$ e $2.000 \mathrm{~m}$ ). Esta bacia está posicionada sobre a borda sul do Cráton de São Francisco, é constituída por terrenos dominantes granulíticos, total ou parcialmente retrabalhados no ciclo

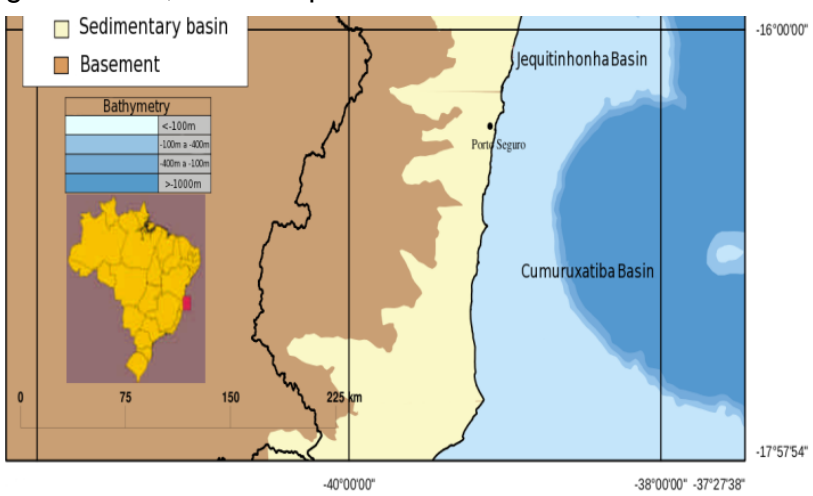

Transamazônico.

Figura 3 - Mapa indicando a localização da Bacia do Jequitinhonha (retirado com modificações de ANP, 2012).

A linha 0026-0297 de Jequitinhonha fez parte de uma aquisição sísmica marinha realizada na Bacia de Jequitinhonha, localizada no sul do Estado da Bahia cuja extensão na superfície é dada por a soma do máximo afastamento da linha e a multiplicação da distância entre as fontes e o número de fontes menos um, é igual a $27.625 \mathrm{~m}$. 


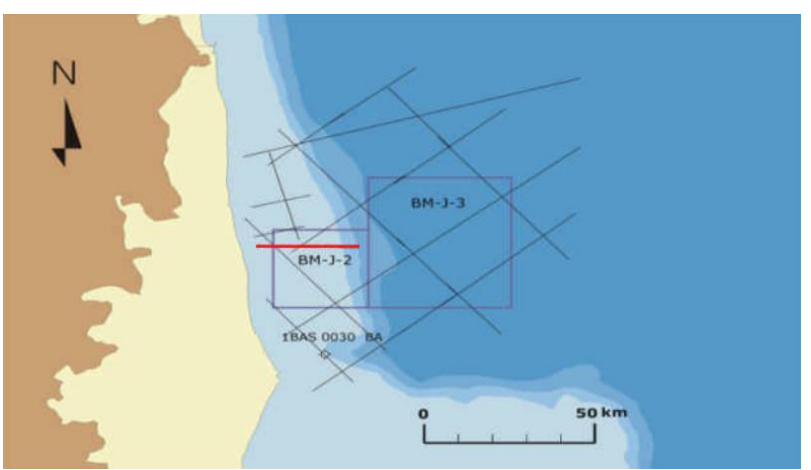

Figura 4 - A linha utilizada, indicada no mapa na cor vermelho, é proveniente do bloco BM-J-2 e situa-se na região de quebra do talude, entre a plataforma continental e a oceânica (retirado com modificações de ANP, 2012).

A Figura 4 mostra a localização da linha 0026-0297 com cor vermelho na região de quebra do talude entre a plataforma continental e a oceânica.

\section{Parâmetros de Aquisição e Processamento}

Os parâmetros de aquisição da linha 0026-0297 estão descritos na Tabela 1. Os dados foram coletados através do levantamento contínuo/sequencial, empregando a técnica CDP e usando o arranjo simétrico. A execução do levantamento se caracterizou por deslocamentos sucessivos no lanço. O comprimento total da linha era de $27.625 \mathrm{~m}$, e o número de canais utilizados por tiro foi de 120.

\begin{tabular}{|c|c|}
\hline Descrição do parâmetro & Valor utilizado \\
\hline Número de fontes & $981 \mathrm{~m}$ \\
\hline Distância entre as fontes & $25 \mathrm{~m}$ \\
\hline Número de canais & 120 \\
\hline Distância entre os canais & $25 \mathrm{~m}$ \\
\hline Afastamento mínimo & $150 \mathrm{~m}$ \\
\hline Afastamento máximo & $3125 \mathrm{~m}$ \\
\hline Canal próximo da fonte & 120 \\
\hline Tempo de registro & 5 segundos \\
\hline
\end{tabular}

Tabela 1 - Parâmetros de aquisição da linha sísmica 0026-0297 da Bacia do Jequitinhonha.

O procedimento empregado para o processamento dos dados foi aplicar o fluxograma da Figura 5. O processamento é dividido em duas fases de execução: as etapas de preparação dos dados ou pré-processamento (como a leitura, a geometria e edição dos dados) e o processamento avançado (como a análise de velocidade e a deconvolução). Não existe uma sequência padrão de etapas a serem adotadas no processamento, entretanto, algumas etapas geralmente estão presentes, como a organização dos traços em famílias de ponto médio comum, análise de velocidade, correção do sobretempo normal (NMO) e empilhamento. Outras etapas importantes nesta fase são a correção de amplitude e a filtragem inicial dos dados.

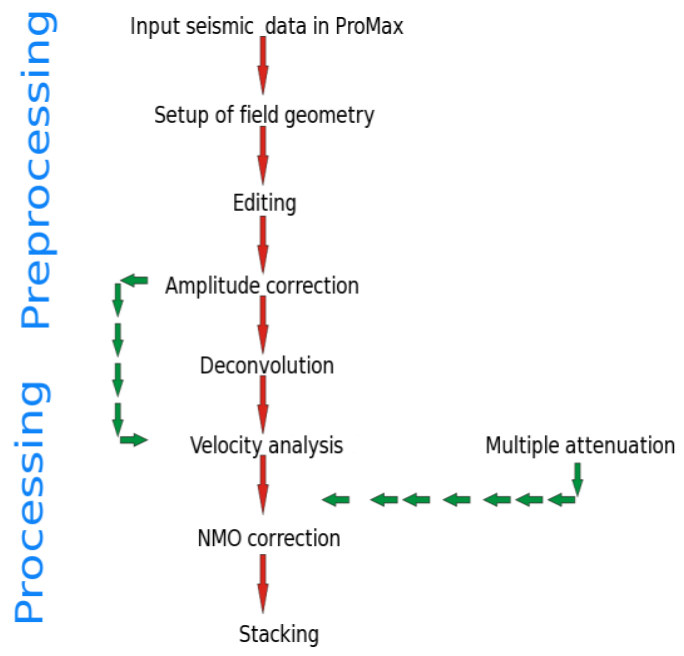

Figura 5 - Fluxo básico de processamento sísmico para a linha sísmica 0026-0297 da Bacia do Jequitinhonha.

Como resultado da correção NMO ocorrem distorções nas frequências especialmente para os eventos mais rasos e de grande afastamento, estas distorções são chamadas de estiramento, no processamento convencional o efeito do estiramento é removido através do muting de um percentual da parte afetada, uma correção não hiperbólica pode corrigir este estiramento sem apagar informações provenientes de afastamentos distantes.

A Figura 6 mostra uma correção NMO hiperbólica dando como resultado uma pequena curva residual entre os tempos de 1 a $2 s$ (afastamento distante), isto é devido a dois possíveis fenômenos: (i) sobrecorreção da hipérbole após a correção normal moveout ou estiramento; (ii) presença de anisotropia no meio.

Ainda na Figura 6 pode-se ver o efeito de estiramento para os tempos de 1 a 2 s e eventos sobrecorrigidos nos grande afastamento embora a velocidade NMO selecionada esteja no ponto de maior coerência do espetro de velocidade.

Para fazer uma correção na curva residual, aplicamos o método do Castle (1994) que utiliza a equação de Malovichko (1978), e o método de Al-Chalabi (1973), observa-se o efeito sobrecorrigidos diminuído nas Figuras 7 e 8. 


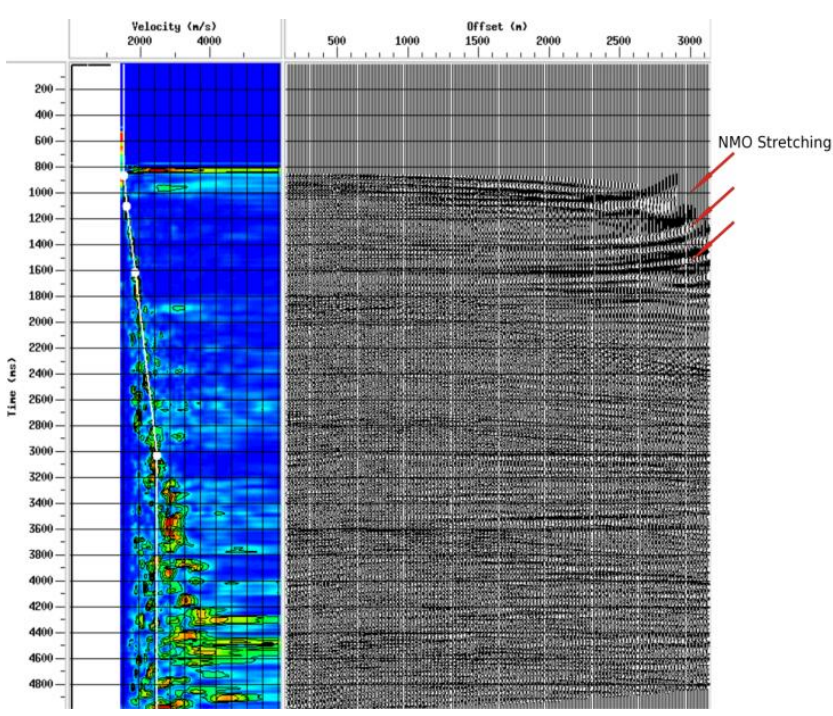

Figura 6 - Correção NMO utilizando a aproximação hiperbólica para o supergather na faixa 927-1026 e CDP central número 977 , e seu respectivo espectro de velocidade. Note-se o efeito de estiramento para afastamentos acima de $2500 \mathrm{~ms}$.

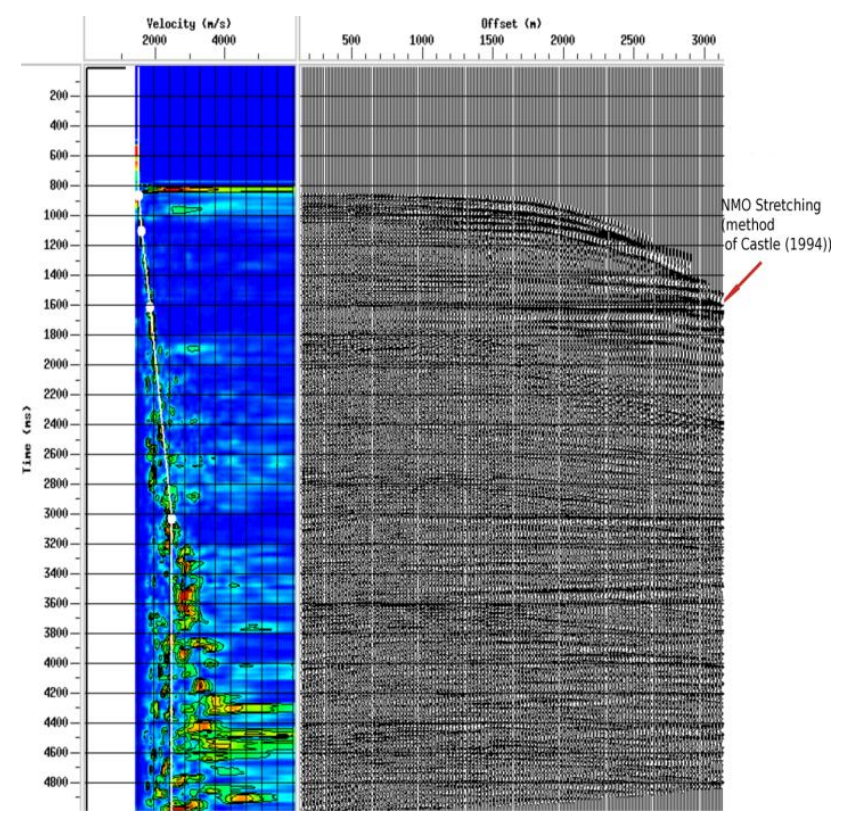

Figura 7 - Correção NMO utilizando a aproximação não hiperbólica para o supergather na faixa 927-1026 e CDP central número 977 (método de Castle), e seu respectivo espectro de velocidade. Em comparação com a Figura 6 , note-se o efeito de estiramento corrigido para afastamentos acima de $2500 \mathrm{~m}$ e tempo em torno de $1600 \mathrm{~ms}$.

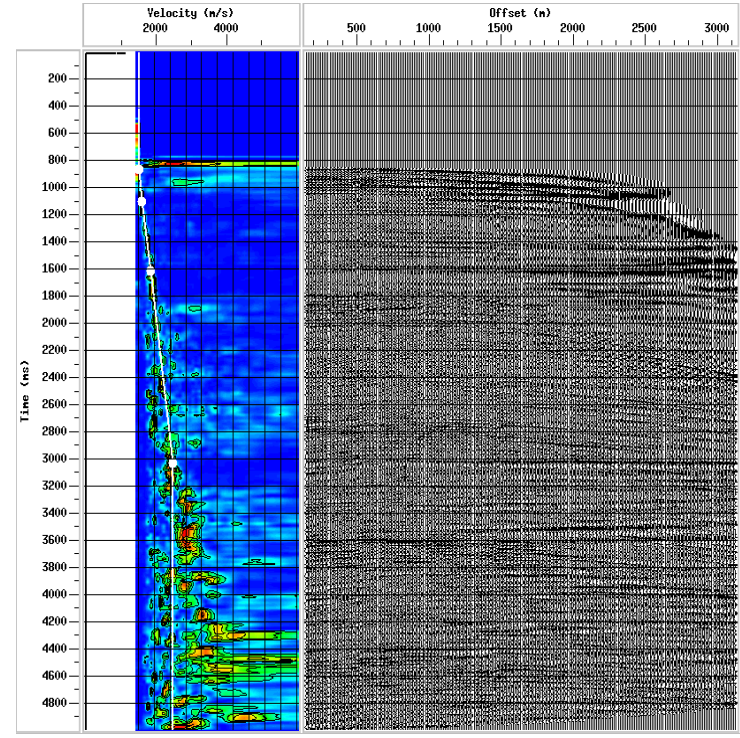

Figura 8 - Correção NMO utilizando a aproximação não hiperbólica para o supergather na faixa 927-1026 e CDP central número 977 (método de Al-Chalabi), e seu respectivo espectro de velocidade. Em comparação com a Figura 6, notese 0 efeito de estiramento corrigido para afastamentos acima de $2500 \mathrm{~m}$ e tempo em torno de $1600 \mathrm{~ms}$.

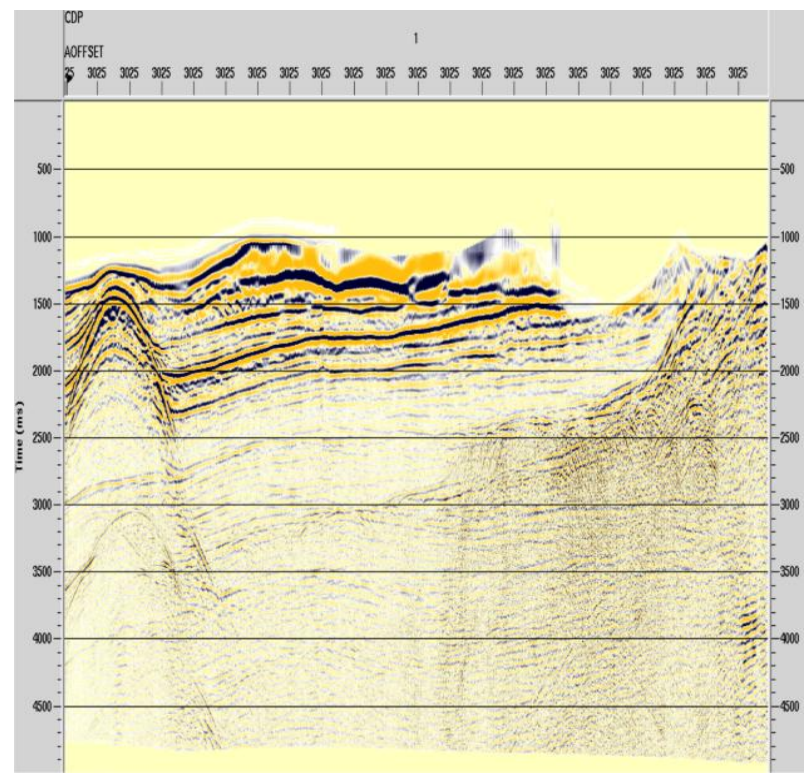

Figura 9 - Seção sísmica utilizando análise de velocidade hiperbólica

Os resultados do processamento são ilustrados nas seções sísmicas das Figuras 9, 10 e 11. Observa-se a diferença entre a correção NMO convencional e a correção de Castle (1994) e Al-Chalabi (1973) na janela de tempo de 1 a $2 \mathrm{~s}$, devido ao aumento da coerência com a equação de Malovichko (1978) e o terceiro termo na equação do tempo que propõem Al-Chalabi (1973). 


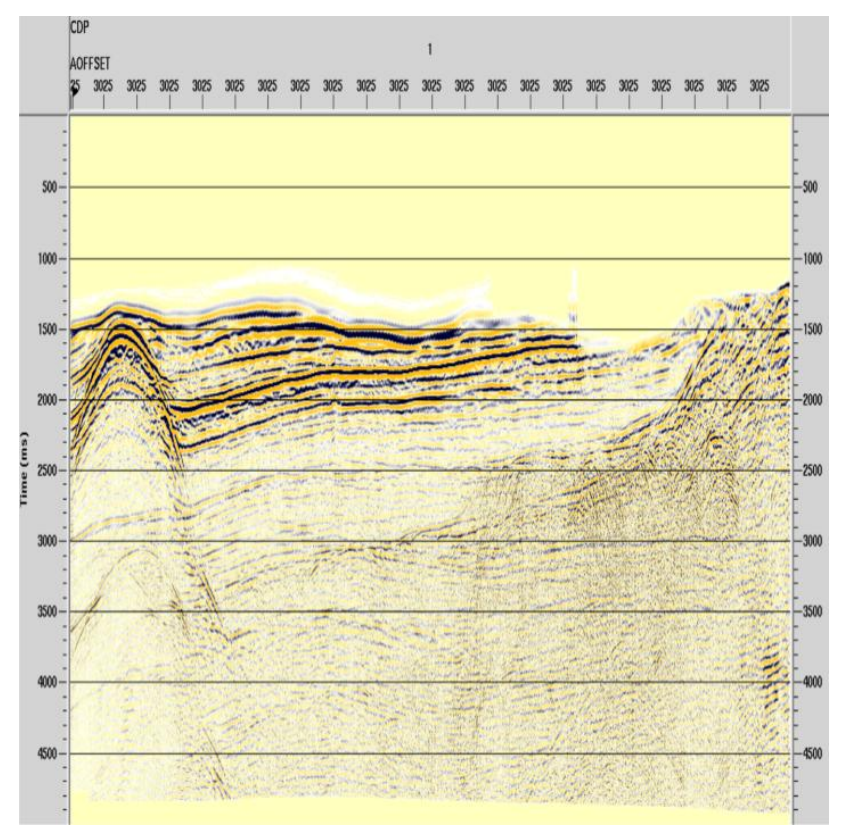

Figura 10 - Seção sísmica utilizando análise de velocidade não hiperbólica pelo método de Castle. Note-se a melhor resolução, e continuidade de refletores entre 1500 e $2000 \mathrm{~ms}$, horizontalidade na região entre os afastamentos de $3025 \mathrm{~m}$.

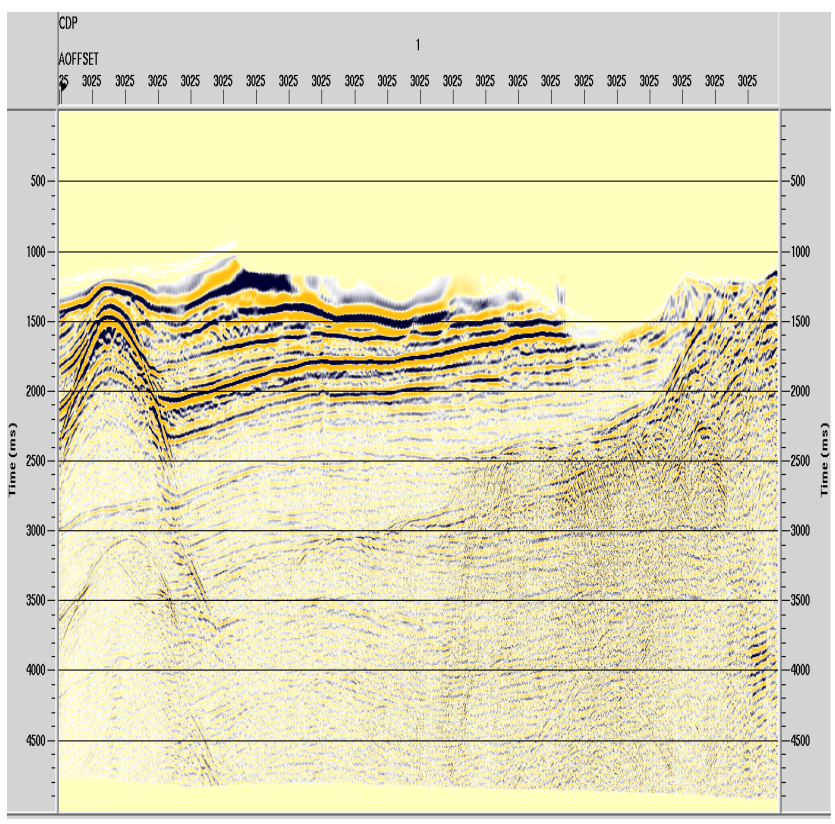

Figura 11 - Seção sísmica utilizando análise de velocidade não hiperbólica pelo método de Al-chalabi. Note-se a melhor resolução, e continuidade de refletores entre 1500 e 2000 ms, horizontalidade na região entre os afastamentos de $3025 \mathrm{~m}$.

\section{Conclusões}

A curva residual esperada para os afastamentos maiores em um meio anisotrópico não é observada nos dados da Bacia do Jequitinhonha já que o máximo afastamento é pequeno comparado à máxima profundidade. A explicação possível na melhoria das imagens é que a análise de velocidade com adição de mais termos na equação de sobretempo normal resulta num aumento de coerência. A curva de tempo representada pelo método Castle mostra uma curva que converge melhor à curva de tempo real proveniente de um refletor plano, esta equação não depende de parâmetros anisotrópicos mais sim do parâmetro $S$ (equação (14)) que, por sua vez, depende do tempo intervar $\Delta t_{k}$ e da velocidade intervalar $V_{k}$ da $k$ ésima camada.

\section{Agradecimentos}

Os autores agradecem à FINEP pelo apoio à Rede Cooperativa de Pesquisa em Geofísica de Exploração (Rede 01 - Fases 3 e 5), à PETROBRAS pela cessão dos dados reais utilizados neste trabalho (Rede 01 Fase 2), e ao CNPq e PETROBRAS pelo apoio ao Instituto Nacional de Ciência e Tecnologia de Geofísica de Petróleo (INCT-GP). F. G. Ortega agradece a CAPES pela bolsa de doutorado. A. Bassrei agradece ao CNPq pelos projetos 307.427/2010-2 e 308.690/2013-3 (bolsa de produtividade de pesquisa),

\section{Referências}

Agência Nacional do Petróleo, Gás Natural e Biocombustíveis ANP. 2012.

Al-Chalabi, M., 1973. Series approximation in velocity and traveltime computations: Geophysical Prospecting, 21: 783-795.

Alkhalifah, T., and Tsvankin, I., 1995. Velocity analysis for transversely isotropic media: Geophysics, 60: 15501566.

Alkhalifah, T., 1997. Velocity analysis using nonhyperbolic moveout in transversely isotropic media: Geophysics, 62: 1839-1854.

Calderón, C., 2003. Procesamiento en tiempo de datos sísmicos de reflexión de ondas $\mathrm{P}$ en medios con anisotropía transversal con eje de simetría vertical (VTI). Trabajo Final de Curso. Universidad Simon Bolivar, Venezuela.

Castle R. J., 1994. A theory of normal moveout: Geophysics, 59: 983-999.

Dix, C. H., 1955. Seismic velocities from surface measurements: Geophysics, 20: 68-86.

Malovichko, A. A., 1978. A new representation of the traveltime curve of reflected waves in horizontally layered media: Geophysics, 91, 47-53. 